\title{
Management of Hypertension among Patients with Coronary Heart Disease
}

\author{
Oladipupo Olafiranye, ${ }^{1,2}$ Ferdinand Zizi, ${ }^{1}$ Perry Brimah, ${ }^{1}$ Girardin Jean-louis, ${ }^{1,3}$ \\ Amgad N. Makaryus, ${ }^{4}$ Samy McFarlane, ${ }^{5}$ and Gbenga Ogedegbe ${ }^{6}$ \\ ${ }^{1}$ Brooklyn Health Disparities Center, Department of Medicine, SUNY Downstate Medical Center, Brooklyn, NY 11203, USA
${ }^{2}$ Division of Cardiovascular Medicine, SUNY Downstate Medical Center, Brooklyn, NY 11203-2098, USA
${ }^{3}$ Sleep Disorders Center, Department of Medicine, SUNY Downstate Medical Center, Brooklyn, NY 11203, USA
${ }^{4}$ Department of Cardiology, North Shore University Hospital, Manhasset, NY 11030, USA
${ }^{5}$ Division of Endocrinology, Diabetes, and Hypertension, SUNY Downstate Medical Center, Brooklyn, NY 11203, USA
${ }^{6}$ Center for Healthful Behavior Change, Division of Internal Medicine, NYU Medical Center, New York, NY 10016, USA
}

Correspondence should be addressed to Oladipupo Olafiranye, oladipupo.olafiranye@downstate.edu

Received 10 May 2011; Accepted 27 May 2011

Academic Editor: Adam T. Whaley-Connell

Copyright (C) 2011 Oladipupo Olafiranye et al. This is an open access article distributed under the Creative Commons Attribution License, which permits unrestricted use, distribution, and reproduction in any medium, provided the original work is properly cited.

\begin{abstract}
Evidence suggests that coronary heart disease (CHD) is the most common outcome of hypertension. Hypertension accelerates the development of atherosclerosis, and sustained elevation of blood pressure (BP) can destabilize vascular lesions and precipitate acute coronary events. Hypertension can cause myocardial ischemia in the absence of CHD. These cardiovascular risks attributed to hypertension can be reduced by optimal BP control. Although several antihypertensive agents exist, the choice of agent and the appropriate target BP for patients with CHD remain controversial. In this succinct paper, we examine the evidence and the mechanisms for the linkage between hypertension and CHD and we discuss the treatment options and the goals of therapy that are consistent with the report of the seventh Joint National Committee on the Prevention, Detection, Evaluation, and Treatment of High Blood Pressure (JNC 7) and American Heart Association scientific statement. We anticipate changes in the recommendations of the forthcoming JNC 8.
\end{abstract}

\section{Background}

Hypertension is not only a major risk factor for stroke and heart failure (HF), but more importantly for coronary heart disease (CHD). Based on the blood pressure (BP) cutoff of $\geq 140 / 90 \mathrm{~mm} \mathrm{Hg}$ for hypertension, as defined by the seventh report of the Joint National Committee on Prevention, Detection, Evaluation, and Treatment of High Blood Pressure (JNC 7) [1], over 65 million adult Americans, or approximately one fourth of the American population, have hypertension [2]. The report of the INTERHEART study involving 52 countries all over the world showed that hypertension conferred a greater adjusted relative risk of acute myocardial infarction than diabetes [3]. Among individuals aged 40 to 90 years, each $20 / 10 \mathrm{~mm} \mathrm{Hg}$ rise in BP doubles the risk of fatal coronary events [4]. Reports of national surveys conducted in various countries in North America, Asia, and Africa indicate that hypertension is highly prevalent, but poorly treated and/or controlled [5]. This observation may be one reason while CHD remains the leading cause of death and disability in the developed countries [6] and is projected to be the leading cause of death in the developing world by 2020 [7-9].

Hypertension accelerates the development and progression of atherosclerosis, and sustained elevation of BP can destabilize vascular lesions and precipitate acute coronary events. Hypertension by itself can cause myocardial ischemia in the absence of CHD. These CVS risks attributed to hypertension can be greatly reduced by optimal control of BP. Although several antihypertensive agents exist, the optimal choice of agents and the appropriate target $\mathrm{BP}$ for patients with $\mathrm{CHD}$ remain controversial. The goals of 
treating patients with hypertension and $\mathrm{CHD}$ are to lower $\mathrm{BP}$, reduce ischemia, and prevent CVS events.

In this succinct paper, we examine the epidemiological evidence and the pathophysiological mechanisms for the linkage between hypertension and CHD and we discuss the treatment options and the goals of therapy that are consistent with the recommendations of JNC 7 and American Heart Association (AHA) scientific statement [1, 10]. As more data from hypertension trials become available, we anticipate changes in the recommendations of the forthcoming JNC 8.

\section{Link between Hypertension and Coronary Heart Disease}

The pathophysiological link between hypertension and CHD can be described under two major pathways as described below and shown in Figure 1.

2.1. Atherogenesis. The physical impact of high BP can cause endothelial injury. Injured endothelium results in impairment in the synthesis and the release of the potent vasodilator-nitric oxide and also promotes the accumulation of reactive oxygen species and other inflammatory factors which mediate the development of atherosclerosis, thrombosis, and vascular occlusion. This inflammatory process is a prominent feature in the pathogenesis of both hypertension and atherosclerosis [11]. Some mechanisms such as the rennin-angiotensin-aldosterone system (RAAS) and the sympathetic nervous system that maintain hypertension are also those that promote atherosclerosis. Angiotensin II increases BP and facilitates progression of atherosclerosis through vasoconstrictive and vascular remodeling effects. This observation led to the idea that some antihypertensive agents such as angiotensin-converting enzyme (ACE) inhibitors may have beneficial effects on atherosclerosis and $\mathrm{CHD}$ in addition to their BP lowering effect [12].

2.2. Increased Afterload and Left Ventricular Hypertrophy. Hypertension by itself can cause myocardial ischemia in the absence of CHD. Increased afterload due to hypertension can result in significant left ventricular hypertrophy (LVH), which may impair ventricular relaxation and compromise coronary blood flow during diastole. Although genetic factors have been associated with LVH, chronic uncontrolled hypertension appears to be the major cause $[13,14]$. Research has shown that LVH diminishes coronary flow reserve [15] and independently predicts future $\mathrm{CHD}, \mathrm{HF}$, stroke, and sudden cardiac death [16].

\section{Therapy for Hypertension in CHD}

Both JNC 7 and 2007 AHA guideline stressed the importance of antihypertensive therapy in the high-risk population, including CHD $[1,9]$. In JNC 7 , target BP was defined for general population and patients with diabetes, HF, and renal disease, but not for those with CHD. However, AHA guideline clarified this issue and recommended the same target $\mathrm{BP}$ of $130 / 80 \mathrm{~mm} \mathrm{Hg}$ as for other high-risk population with caution in lowering the DBP below $60 \mathrm{mmHg}$ which may impair coronary perfusion. The goals of treating

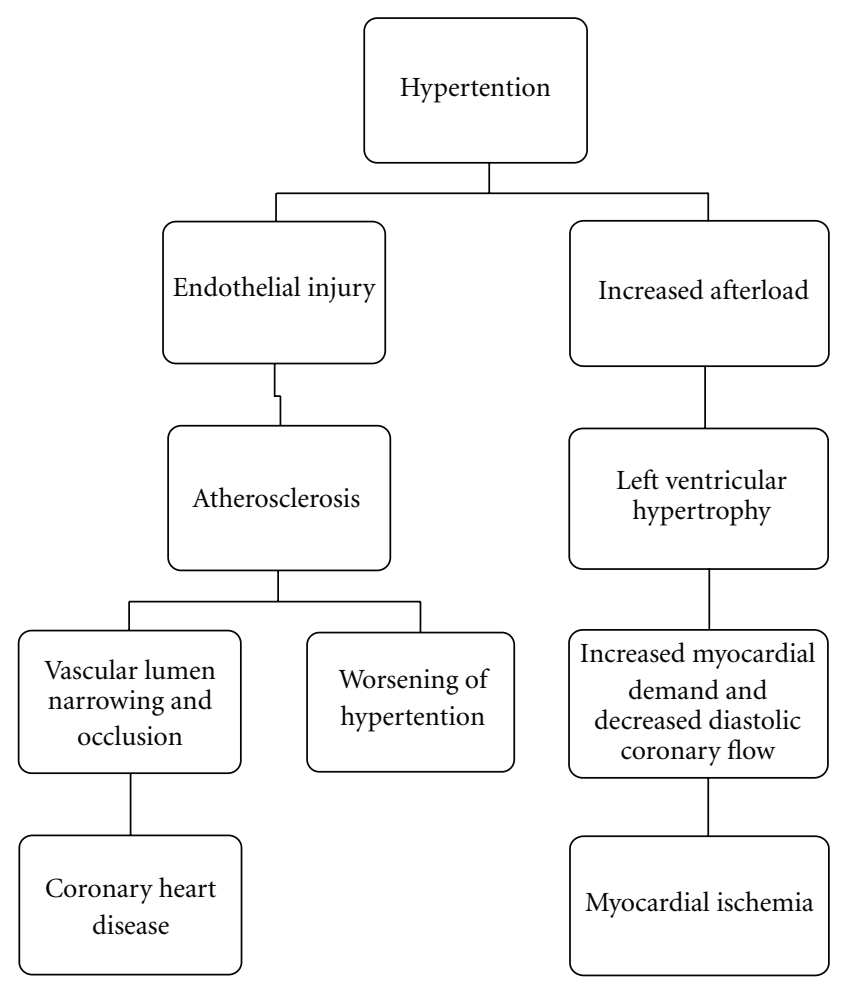

Figure 1: Pathophysiological link between hypertension and coronary heart disease.

hypertension in patients with $\mathrm{CHD}$ are to lower $\mathrm{BP}$, reduce ischemia, and prevent cardiovascular events and death. To achieve these goals, both nonpharmacological interventions and pharmacological therapy are recommended as described below.

3.1. Nonpharmacological Interventions. Nonpharmacological interventions should be encouraged in all individuals with hypertension [1]. Exercise improves cardiac function, reduces BP and cardiac afterload by a variety of mechanisms, including reduced arterial stiffness [17]. Research has shown that physical activity predicts the likelihood of CVS disease beyond that explained by the commonly measured cardiometabolic risk factors [18]. Although the mechanism is not entirely clear, evidence indicates that exercise improves coronary artery flow reserves in CHD patients [19] and pathophysiological mechanisms that are potentially important in generating CHD have been linked to physical activity [20]. Hence, regular exercise is recommended in all individuals with hypertension and CHD.

Studies have also shown that various lifestyle behaviors, including unhealthy diet, physical inactivity, and smoking, promote the development and clinical manifestations of CHD [21]. Therefore, lifestyle changes and adoption of healthful behaviors are equally important in the management of hypertension and CHD. Special attention should be given to weight loss, diet control, salt intake, alcohol consumption, smoking, and stress management.

3.2. Pharmacological Treatment. Pharmacological treatment is inevitable in high-risk populations such as those with 
CHD, although lifestyle modifications alone may suffice in the general population with prehypertension. The recommended target BP for individuals with $\mathrm{CHD}$ or $\mathrm{CHD}$ equivalents: diabetes mellitus, chronic renal disease, peripheral arterial disease, carotid artery disease, and abdominal aortic aneurysm is $<130 / 80 \mathrm{~mm} \mathrm{Hg}$ [9]. Although several antihypertensive agents exist, it is not completely clear whether all antihypertensive agents are equally effective in preventing or decreasing progression of CHD. Here, we discuss each agent and provide the evidence in support of their use.

3.3. Beta-Blockers. The treatment of hypertension in CHD patients should begin with $\beta$-blockers as first-line therapy, unless contraindicated [22-25]. Relative contraindications to their use include hypotension, severe bronchospastic lung disease, decompensated HF, sinus or atrioventricular node dysfunction, and severe peripheral vascular disease. Also, diabetic patients with significant history of hypoglycemic episodes should use $\beta$-blockers with great caution because of the risk of masking symptoms of hypoglycemia.

$\beta$-blockers are heterogenous class of agents with differing pharmacological effects. The cardioselective $\beta$-blockers without intrinsic sympathomimetic activity are generally preferred. These agents reduce myocardial oxygen consumption and heart rate and enhance coronary flow by increasing diastolic filling period. Among patients with both acute myocardial infarction (MI) and hypertension, $\beta$-Blockers have been shown to limit infarct size, improve survival, and decrease the risk of recurrent $\mathrm{MI}$ and the incidence of sudden cardiac death, which is secondary to fatal arrhythmias [26-28]. While metoprolol, carvedilol, and bisoprolol were shown to improve outcomes in HF patients, atenololbased therapy was found to be inferior to amlodipine-based therapy in reducing CVS events in the Anglo-Scandinavian Cardiac Outcomes Trial (ASCOT) [29]. Similarly, a substudy of ASCOT, the Conduit Artery Function Evaluation (CAFÉ), showed that Atenolol was less effective in reducing systolic BP and cardiac afterload than amlodipine [30], which perhaps could be explained by the observation of increased arterial stiffness and aortic wave reflections in patients using betablockers [31]. Hence, in the absence of MI, CHD, or HF, the use of $\beta$-blockers as first-line therapy for hypertension is controversial and not supported.

3.4. Calcium Channel Blockers. Long-acting dihydropyridines calcium channel blockers (CCBs), amlodipine, and nifedipine can be added to the basic regimen if $\mathrm{BP}$ remains elevated or angina continues while on $\beta$-blocker therapy. The nondihydropyridine agents, diltiazem and verapamil, can also be substituted for $\beta$-blocker when contraindications exist or side effects develop [32]. Although nondihydropyridine CCBs can be used as antianginal in combination with a $\beta$-blocker, there is associated risk of severe bradycardia or atrioventricular block. Therefore, if a CCB is needed in addition to $\beta$-blocker to control angina or $\mathrm{BP}$, it should be a long-acting dihydropyridine CCB. These agents decrease BP by causing vasodilation and decreasing peripheral resistance and wall tension, thus reducing myocardial $\mathrm{O}_{2}$ demand.
They also increase myocardial $\mathrm{O}_{2}$ supply by dilating coronary arteries.

Several large randomized trials have evaluated the use of CCBs in hypertension control. The Controlled-Onset Verapamil IN Cardiovascular Endpoint (CONVINCE) trial, the NORdic DILtiazem (NORDIL) study, and the International VErapamil SR/Trandolapril (INVEST) study showed that outcomes with CCBs-based therapy were not different from those of $\beta$-blockers-based therapy [33-35]. Based on these studies, CCBs appear to be good substitutes for $\beta$-blockers in the treatment of angina in hypertensive patients; however, they are not recommended for secondary prevention because of their inability to prevent ventricular dilatation and HF [36-40]. Hence, nondihydropyridine agents should not be used in patients with systolic HF [41] and short-acting dihydropyridine CCBs should be avoided in patients with acute MI, pulmonary edema, or LV dysfunction [24, 42, 43]. The role of CCBs in the prevention of CVS events among patients with CHD remains unclear, and several studies that evaluated CVS outcome with the use of CCBs have yielded mixed results $[35,37-40,44,45]$.

3.5. Nitrates. Nitrates have not been shown to be of significant use in hypertension treatment; however, they are indicated for acute relief of angina or treatment of chronic angina which cannot be controlled with $\beta$-blockers and CCBs. The reports of two large trials comparing nitrates with placebo showed no difference in mortality with the use of nitrates $[46,47]$. Hence, nitrates are not recommended to reduce cardiac events but only to relieve angina, control BP, and manage pulmonary congestion. Nitrates combined with hydralazine have survival benefit in selected HF patients [41]. However, individuals taking nitrates should be advised not to use phosphodiesterase inhibitors such as sildenafil, as the combination of both may cause severe hypotension.

3.6. Angiotensin-Converting Enzyme. ACE inhibitors are recommended for use in all patients after MI. Two major trials, the European Trial on Reduction of Cardiac Events with Perindopril in Stable Coronary Artery Disease (EUROPA) and Heart Outcome Prevention Evaluation (HOPE) study, showed the cardioprotective effect of ACE inhibitor in hypertensive CHD patients [48-51]. In the EUROPA study, 12,218 patients were randomized to treatment with an ACE inhibitor (perindopril) or placebo. Individuals in the perindopril group had significantly less MI, CVS death, or cardiac arrest [48]. The HOPE study involved 9,297 patients with CVS risk factors, who were randomized to ramipril or placebo. Approximately half of the study population had hypertension. Ramipril therapy was associated with small $(3 / 2 \mathrm{~mm} \mathrm{Hg})$ reduction in BP but significant reduction in CVS death, stroke, and MI $[49,50]$. These cardioprotective effects were initially thought to be independent of $\mathrm{BP}$ control, until a subgroup analysis of the HOPE trial revealed a significant reduction in 24-hour ambulatory BP with ramipril that was not found in the main trial that measured only office BP [51]. In another trial, the Prevention of Events with Angiotensin Converting Enzyme inhibition (PEACE), involving stable $\mathrm{CHD}$ patients with normal or slightly 
reduced ejection fraction, there was no difference between trandolapril therapy and placebo in the incidence of MI or coronary revascularization, despite $4.4 / 3.6 \mathrm{~mm} \mathrm{Hg}$ reduction in BP [52]. The findings of this study raised question about the usefulness of ACE inhibitors in low-risk CHD patients with normal LV systolic function. Thus, ACE inhibitors are indicated for all hypertensive patients with acute MI who have no contraindications, especially if there is associated depressed LV systolic function $(\operatorname{LVEF}<40 \%)[53,54]$.

3.7. Angiotensin-Receptor Blockers. In individuals who are ACE inhibitor intolerant or allergic, angiotensin receptors blockers (ARBs) have been shown to be an effective alternative in the treatment of hypertension, $\mathrm{CHD}$, and $\mathrm{HF}$. Emerging data appear to support the use of ARBs in MI. In the VALIANT study, the ARB, valsartan was as effective as captopril in patients at high risk of CVS events after MI [55, 56]. Among 15,245 hypertensive patients that were enrolled in the Valsartan Antihypertensive Long-term Use Evaluation (VALUE) trial, the ARB, valsartan, and CCB, amlodipine had similar primary protection against CVS events [40]. Hence, ARB appears to be a good substitute in those individuals in which ACEI is contraindicated.

3.8. Diuretic. The ALLHAT trial clearly showed the benefit of thiazide diuretic in the treatment of hypertension [3739], although there are concerns about the contribution of the metabolic effects of thiazide to $\mathrm{CHD}$ risk [57]. The effectiveness of thiazide in controlling BP and preventing CVS events has been demonstrated in several studies [5860 ], but their use in the setting of acute MI is not encouraged and if at all required, should be done with caution. While there is an ongoing debate over whether the clinical benefits observed with thiazide-type diuretic are drug specific, it is not unreasonable to assume that there is a "class effect," given the high degree of homogeneity in the mechanism of action of this group of antihypertensive agents.

3.9. Combination and Adjunctive Therapy. The control of $\mathrm{BP}$ is more important than the choice of antihypertensive agent in the prevention $\mathrm{CHD}$ and other complications of hypertension $[61,62]$. Research has shown that effective combination of antihypertensive agents is usually required to achieve and sustain long-term BP control [1]. Therefore, the most important strategy for achieving target BP level is by using combination therapy most especially in individuals with stage 2 hypertension. Other adjunctive therapies such as antiplatelet therapy and the use of statins are also encouraged for lowering atherosclerotic burden in CHD patients. Nonpharmacological therapy such as regular exercise, smoking cessation, healthy diet, and healthful psychosocial functioning should be emphasized in all patients, even when antihypertensive agents are being used.

\section{Conclusion}

The target $\mathrm{BP}$ in hypertensive patients with $\mathrm{CHD}$ is $<130 / 80 \mathrm{~mm} \mathrm{Hg}$ with caution in lowering the DBP below $60 \mathrm{~mm} \mathrm{Hg}$. To achieve this target, effective combination antihypertensive drug therapy is usually required to achieve and sustain long-term BP control. Treatment regimen should include $\beta$-blocker, ACE inhibitor, or ARB, most especially if there is LV systolic dysfunction and/or diabetes mellitus, and possibly a thiazide diuretic. CCBs can be used as alternative to $\beta$-blocker or added to the basic regimen, and nitrates are useful for relieve of ischemic pain. The overall goal of therapy is to reduce morbidity and mortality associated with both hypertension and CHD. As more data from hypertension trials are made available, we anticipate changes in the recommendations of the forthcoming JNC 8.

\section{Acknowledgment}

This research was supported by funding from the NIH (R25HL105444 and R01MD004113).

\section{References}

[1] A. V. Chobanian, G. L. Bakris, H. R. Black et al., "Seventh report of the joint national committee on prevention, detection, evaluation, and treatment of high blood pressure," Hypertension, vol. 42, pp. 1206-1252, 2003.

[2] V. L. Burt, P. Whelton, E. J. Roccella et al., "Prevalence of hypertension in the US adult population: results from the 3rd National Health and Nutrition Examination Survey, 19881991," Hypertension, vol. 25, no. 3, pp. 305-313, 1995.

[3] P. S. Yusuf, S. Hawken, S. Ônpuu et al., "Effect of potentially modifiable risk factors associated with myocardial infarction in 52 countries (the INTERHEART study): case-control study," The Lancet, vol. 364, no. 9438, pp. 937-952, 2004.

[4] S. Lewington, R. Clarke, N. Qizilbash, R. Peto, and R. Collins, "Age-specific relevance of usual blood pressure to vascular mortality: a meta-analysis of individual data for one million adults in 61 prospective studies," The Lancet, vol. 360, no. 9349, pp. 1903-1913, 2002.

[5] P. K. Whelton, J. He, and P. Muntner, "Prevelance, awareness, treatment and control of hypertension in North America, North Africa and Asia," Journal of Human Hypertension, vol. 18 , no. 8, pp. 545-551, 2004.

[6] American Heart Association, Heart Disease and Stroke Statistics-2007 Update, American Heart Association, Dallas, Tex, USA, 2007.

[7] C. J. Murray and A. D. Lopez, The Global Burden of Disease: A Comprehensive Assessment of Mortality and Disability from Diseases, Injuries and Risk Factors in 1990 and Projected to 2020, vol. 1 of Global Burden of Disease and Injury Series, Harvard School of Public Health, Cambridge, Mass, USA, 1996.

[8] S. Ôunpuu, A. Negassa, and S. Yusuf, "INTER-HEART: a global study of risk factors for acute myocardial infarction," American Heart Journal, vol. 141, no. 5, pp. 711-721, 2001.

[9] K. Okrainec, D. K. Banerjee, and M. J. Eisenberg, "Coronary artery disease in the developing world," American Heart Journal, vol. 148, no. 1, pp. 7-15, 2004.

[10] C. Rosendorff, H. R. Black, C. P. Cannon et al., "Treatment of hypertension in the prevention and management of ischemic heart disease: a scientific statement from the American Heart Association council for high blood pressure research and the councils on clinical cardiology and epidemiology and prevention," Circulation, vol. 115, no. 21, pp. 2761-2788, 2007.

[11] S. Oparil, M. A. Zaman, and D. A. Calhoun, "Pathogenesis of hypertension," Annals of Internal Medicine, vol. 139, no. 9, pp. 761-776, 2003. 
[12] V. Dzau, "The cardiovascular continuum and reninangiotensin-aldosterone system blockade," Journal of Hypertension, vol. 23, no. 1, supplement, pp. S9-S17, 2005.

[13] D. Levy, K. M. Anderson, D. D. Savage, W. B. Kannel, J. C. Christiansen, and W. P. Castelli, "Echocardiographically detected left ventricular hypertrophy: prevalence and risk factors. The Framingham heart study," Annals of Internal Medicine, vol. 108, no. 1, pp. 7-13, 1988.

[14] P. Rheeder, R. P. Stolk, A. Mosterd, H. A. P. Pols, A. Hofman, and D. E. Grobbee, "Insulin resistance syndrome and left ventricular mass in an elderly population (the Rotterdam study)," American Journal of Cardiology, vol. 84, no. 2, pp. 233 236, 1999.

[15] E. D. Frohlich, "Hypertension, left ventricular hypertrophy, and coronary flow reserve," Advances in Experimental Medicine and Biology, vol. 432, pp. 253-262, 1997.

[16] W. B. Kannel and P. W. F. Wilson, "Cardiovascular risk factors and hypertension," in Hypertension Primer, J. L. Izzo Jr. and H. R. Black, Eds., pp. 235-238, American Heart Association, Dallas, Tex, USA, 3rd edition, 2003.

[17] P. V. Vaitkevicius, J. L. Fleg, J. H. Engel et al., "Effects of age and aerobic capacity on arterial stiffness in healthy adults," Circulation, vol. 88, no. 4, pp. 1456-1462, 1993.

[18] K. A. McGuire, I. Janssen, and R. Ross, "Ability of physical activity to predict cardiovascular disease beyond commonly evaluated cardiometabolic risk factors," American Journal of Cardiology, vol. 104, no. 11, pp. 1522-1526, 2009.

[19] R. Hambrecht, A. Wolf, S. Gielen et al., "Effect of exercise on coronary endothelial function in patients with coronary artery disease," New England Journal of Medicine, vol. 342, no. 7, pp. 454-460, 2000.

[20] A. E. Bauman, "Updating the evidence that physical activity is good for health: an epidemiological review 2000-2003," Journal of Science and Medicine in Sport, vol. 7, no. 1, pp. 619, 2004.

[21] A. Rozanski, J. A. Blumenthal, and J. Kaplan, "Impact of psychological factors on the pathogenesis of cardiovascular disease and implications for therapy," Circulation, vol. 99, no. 16, pp. 2192-2217, 1999.

[22] E. M. Antman, D. T. Anbe, P. W. Armstrong et al., "ACC/AHA guidelines for the management of patients with ST-elevation myocardial infarction: executive summary: a report of the ACC/AHA Task Force on Practice Guidelines (Committee to Revise the 1999 Guidelines for the Management of Patients With Acute Myocardial Infarction)," Circulation, vol. 110, pp. 588-636, 2004.

[23] E. M. Antman, D. T. Anbe, P. W. Armstrong et al., "ACC/AHA guidelines for the management of patients with ST-elevation myocardial infarction: executive summary: a report of the ACC/AHA Task Force on Practice Guidelines (Committee to Revise the 1999 Guidelines for the Management of Patients With Acute Myocardial Infarction)," Circulation, vol. 111, p. 2013, 2005.

[24] R. J. Gibbons, J. Abrams, K. Chatterjee et al., "ACC/AHA 2002 guideline update for the management of patients with chronic stable angina-summary article: a report of the American College of Cardiology/American Heart Association Task Force on Practice Guidelines (Committee on the Management of Patients With Chronic Stable Angina)," Journal of the American College of Cardiology, vol. 41, no. 1, pp. 159-168, 2003.

[25] J. G. Wang and J. A. Staessen, "Benefits of antihypertensive pharmacologic therapy and blood pressure reduction in outcome trials," Journal of Clinical Hypertension, vol. 5, no. 1, pp. 66-75, 2003.

[26] S. Viskin, I. Kitzis, E. Lev et al., "Treatment with betaadrenergic blocking agents after myocardial infarction: from randomized trials to clinical practice," Journal of the American College of Cardiology, vol. 25, no. 6, pp. 1327-1332, 1995.

[27] S. Goldstein, " $\beta$-Blockers in hypertensive and coronary heart disease," Archives of Internal Medicine, vol. 156, no. 12, pp. 1267-1276, 1996.

[28] W. H. Frishman and A. Cheng, "Secondary prevention of myocardial infarction: role of $\beta$-adrenegic blockers and angiostein converting enzyme inhibitors," American Heart Journal, vol. 137, pp. S25-S34, 1999.

[29] B. Dahlöf, P. S. Sever, N. R. Poulter et al., "Prevention of cardiovascular events with an antihypertensive regimen of amlodipine adding perindopril as required versus atenolol adding bendroflumethiazide as required, in the AngloScandinavian Cardiac Outcomes Trial-Blood Pressure Lowering Arm (ASCOT-BPLA): a multicentre randomised controlled trial," The Lancet, vol. 366, no. 9489, pp. 895-906, 2005.

[30] B. Williams, P. S. Lacy, S. M. Thom et al., "Differential impact of blood pressure-lowering drugs on central aortic pressure and clinical outcomes: principal results of the Conduit Artery Function Evaluation (CAFÉ) study," Circulation, vol. 113, no. 9, pp. 1213-1225, 2006.

[31] O. Olafiranye, G. Qureshi, L. Salciccioli, M. Weber, and J. M. Lazar, "Association of beta-blocker use with increased aortic wave reflection," Journal of the American Society of Hypertension, vol. 2, no. 2, pp. 64-69, 2008.

[32] C. Rosendorff, "Calcium antagonists in the treatment of hypertension in patients with ischaemic heart disease," Expert Opinion on Pharmacotherapy, vol. 4, no. 9, pp. 1535-1541, 2003.

[33] H. R. Black, W. J. Elliott, G. Grandits et al., "Principal results of the controlled onset verapamil investigation of cardiovascular end points (CONVINCE) trial," Journal of the American Medical Association, vol. 289, no. 16, pp. 2073-2082, 2003.

[34] L. Hansson, T. Hedner, P. Lund-Johansen et al., "Randomised trial of effects of calcium antagonists compared with diuretics and $\beta$-blockers on cardiovascular morbidity and mortality in hypertension: the Nordic Diltiazem (NORDIL) study," The Lancet, vol. 356, no. 9227, pp. 359-365, 2000.

[35] C. J. Pepine, E. M. Handberg, R. M. Cooper-DeHoff et al., "A calcium antagonist vs a non-calcium antagonist hypertension treatment strategy for patients with coronary artery disease the international verapamil-trandolapril study (INVEST): a randomized controlled trial," Journal of the American Medical Association, vol. 290, no. 21, pp. 2805-2816, 2003.

[36] R. E. Goldstein, S. J. Boccuzzi, D. Cruess et al., "Diltiazem increases late-onset congestive heart failure in postinfarction patients with early reduction in ejection fraction," Circulation, vol. 83, pp. 52-60, 1991.

[37] ALLHAT-Officers and Coordinators for the ALLHAT Collaborative Research Group, "Major outcomes in high-risk hypertensive patients randomized to angiotensin-converting enzyme inhibitor or calcium channel blocker vs diuretic: the Antihypertensive and Lipid-Lowering Treatment to Prevent Heart Attack Trial (ALLHAT)," Journal of the American Medical Association, vol. 288, pp. 2981-2997, 2002.

[38] ALLHAT-Officers and Coordinators for the ALLHAT Collaborative Research Group, "Major outcomes in high-risk hypertensive patients randomized to angiotensin-converting enzyme inhibitor or calcium channel blocker vs diuretic: the 
Antihypertensive and Lipid-Lowering Treatment to Prevent Heart Attack Trial (ALLHAT)," Journal of the American Medical Association, vol. 289, p. 178, 2003.

[39] ALLHAT-Officers and Coordinators for the ALLHAT Collaborative Research Group, "Major outcomes in high-risk hypertensive patients randomized to angiotensin-converting enzyme inhibitor or calcium channel blocker vs diuretic: the Antihypertensive and Lipid-Lowering Treatment to Prevent Heart Attack Trial (ALLHAT)," Journal of the American Medical Association, vol. 291, p. 2196, 2004.

[40] S. Julius, S. E. Kjeldsen, M. Weber et al., "Outcomes in hypertensive patients at high cardiovascular risk treated with regimens based on valsartan or amlodipine: the VALUE randomised trial," The Lancet, vol. 363, no. 9426, pp. 20222031, 2004.

[41] S. A. Hunt, W. T. Abraham, M. H. Chin et al., "ACC/AHA 2005 guideline update for the diagnosis and management of chronic heart failure in the adult: a report of the American College of Cardiology/American Heart Association Task Force on Practice Guidelines (Writing Committee to Update the 2001 Guidelines for the Evaluation and Management of Heart Failure): developed in collaboration with the American College of Chest Physicians and the International Society for Heart and Lung Transplantation: endorsed by the Heart Rhythm Society," Circulation, vol. 112, pp. e154-e235, 2005.

[42] M. H. Alderman, H. Cohen, R. Roqué, and S. Madhavan, "Effect of long-acting and short-acting calcium antagonists on cardiovascular outcomes in hypertensive patients," The Lancet, vol. 349, no. 9052, pp. 594-598, 1997.

[43] C. H. Hennekens, C. M. Albert, S. L. Godfried, J. M. Gaziano, and J. E. Buring, "Drug therapy: adjunctive drug therapy of acute myocardial infarction-evidence from clinical trials," New England Journal of Medicine, vol. 335, no. 22, pp. 16601667, 1996.

[44] F. Turnbull, "Effects of different blood-pressure-lowering regimens on major cardiovascular events: results of prospectivelydesigned overviews of randomised trials," The Lancet, vol. 362, no. 9395, pp. 1527-1535, 2003.

[45] R. P. Mason, "Mechanisms of plaque stabilization for the dihydropyridine calcium channel blocker amlodipine: review of the evidence," Atherosclerosis, vol. 165, no. 2, pp. 191-199, 2002.

[46] ISIS-4 (Fourth International Study of Infarct Survival) Collaborative Group, "ISIS-4: a randomised factorial trial assessing early oral captopril, oral mononitrate, and intravenous magnesium sulphate in 58,050 patients with suspected acute myocardial infarction," The Lancet, vol. 345, pp. 669-685, 1995.

[47] Gruppo Italiano per lo Studio della Sopravvivenza nell'infarto Miocardico, "GISSI-3: effects of lisinopril and transdermal glyceryl trinitrate singly and together on 6-week mortality and ventricular function after acute myocardial infarction," The Lancet, vol. 343, pp. 1115-1122, 1994.

[48] K. M. Fox and EURopean Trial on Reduction of Cardiac Events with Perindopril in Stable Coronary Artery Disease Investigators, "Efficacy of perindopril in reduction of cardiovascular events among patients with stable coronary artery disease: randomised, double-blind, placebo-controlled, multicentre trial (the EUROPA study)," The Lancet, vol. 362, pp. 782-788, 2003.

[49] S. Yusuf, P. Sleight, J. Pogue, J. Bosch, R. Davies, and G. Dagenais, "Effects of an angiotensin-converting-enzyme inhibitor, ramipril, on cardiovascular events in high-risk patients: the
Heart Outcomes Prevention Evaluation study," New England Journal of Medicine, vol. 342, pp. 145-153, 2000.

[50] S. Yusuf, P. Sleight, J. Pogue, J. Bosch, R. Davies, and G. Dagenais, "Effects of an angiotensin-converting-enzyme inhibitor, ramipril, on cardiovascular events in high-risk patients: the Heart Outcomes Prevention Evaluation study," New England Journal of Medicine, vol. 342, p. 1376, 2000.

[51] P. Svensson, U. de Faire, P. Sleight, S. Yusuf, and J. Ostergren, "Comparative effects of ramipril on ambulatory and office blood pressures: a HOPE substudy," Hypertension, vol. 38, no. 6, pp. E28-E32, 2001.

[52] E. Braunwald, M. J. Domanski, S. E. Fowler et al., "Angiotensin-converting-enzyme inhibition in stable coronary artery disease," New England Journal of Medicine, vol. 351, no. 20, pp. 2058-2068, 2004.

[53] ACE Inhibitor Myocardial Infarction Collaborative Group, "Indications for ACE inhibitors in the early treatment of acute myocardial infarction: systematic overview of individual data from 100000 patients in randomized trials," Circulation, vol. 97, no. 22, pp. 2202-2212, 1998.

[54] M. D. Flather, S. Yusuf, L. Køber et al., "Long-term ACEinhibitor therapy in patients with heart failure or leftventricular dysfunction: a systematic overview of data from individual patients," The Lancet, vol. 355, no. 9215, pp. 15751581, 2000.

[55] M. A. Pfeffer, J. J. V. McMurray, E. J. Velazquez et al., "Valsartan, captopril, or both in myocardial infarction complicated by heart failure, left ventricular dysfunction, or both," New England Journal of Medicine, vol. 349, no. 20, pp. 1893-1906, 2003.

[56] M. A. Pfeffer, J. J. V. McMurray, E. J. Velazquez et al., "Valsartan, captopril, or both in myocardial infarction complicated by heart failure, left ventricular dysfunction, or both," New England Journal of Medicine, vol. 350, p. 203, 2004.

[57] P. Verdecchia, G. Reboldi, F. Angeli et al., "Adverse prognostic significance of new diabetes in treated hypertensive subjects," Hypertension, vol. 43, no. 5, pp. 963-969, 2004.

[58] SHEP Cooperative Research Group, "Prevention of stroke by antihypertensive drug treatment in older persons with isolated systolic hypertension: final results of the Systolic Hypertension in the Elderly Program (SHEP)," Journal of the American Medical Association, vol. 265, no. 24, pp. 3255-3264, 1991.

[59] "Effects of treatment on morbidity in hypertension, II: results in patients with diastolic blood pressure averaging 90 through $114 \mathrm{~mm}$ Hg," Journal of the American Medical Association, vol. 213, pp. 1143-1152, 1970.

[60] Medical Research Council Working Party, "MRC trial of treatment of mild hypertension: principal results," British Medical Journal, vol. 291, no. 6488, pp. 97-104, 1985.

[61] J. G. Wang and J. A. Staessen, "Benefits of antihypertensive pharmacologic therapy and blood pressure reduction in outcome trials," Journal of Clinical Hypertension, vol. 5, no. 1, pp. 66-75, 2003.

[62] J. A. Staessen, J.-G. Wang, and L. Thijs, "Cardiovascular prevention and blood pressure reduction: a quantitative overview updated until 1 March 2003," Journal of Hypertension, vol. 21, no. 6, pp. 1055-1076, 2003. 


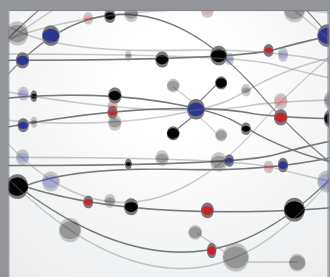

The Scientific World Journal
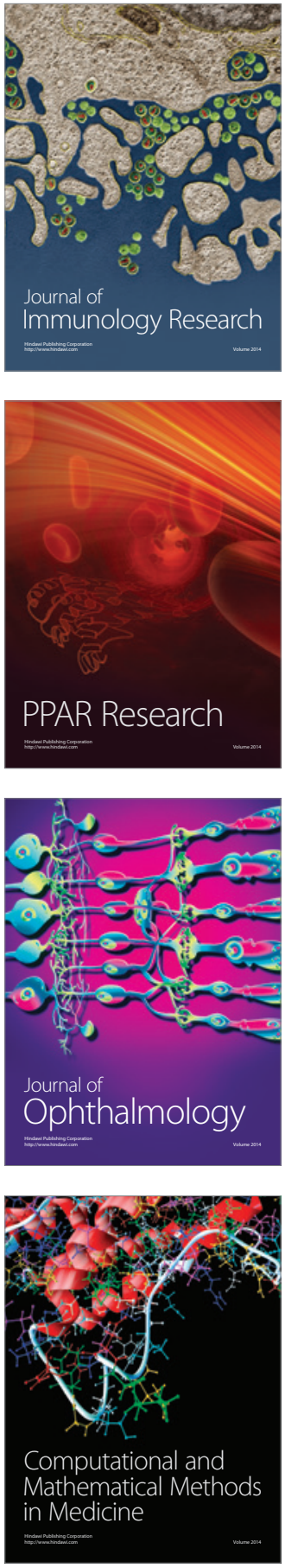

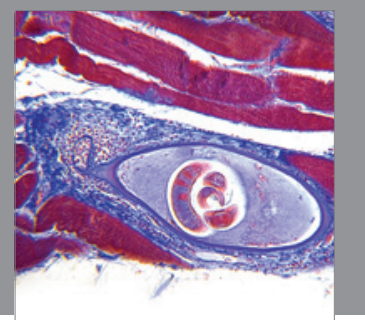

Gastroenterology

Research and Practice
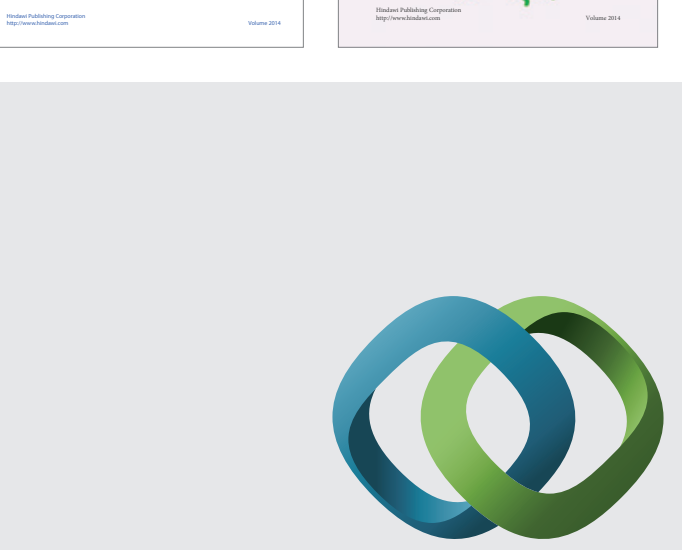

\section{Hindawi}

Submit your manuscripts at

http://www.hindawi.com
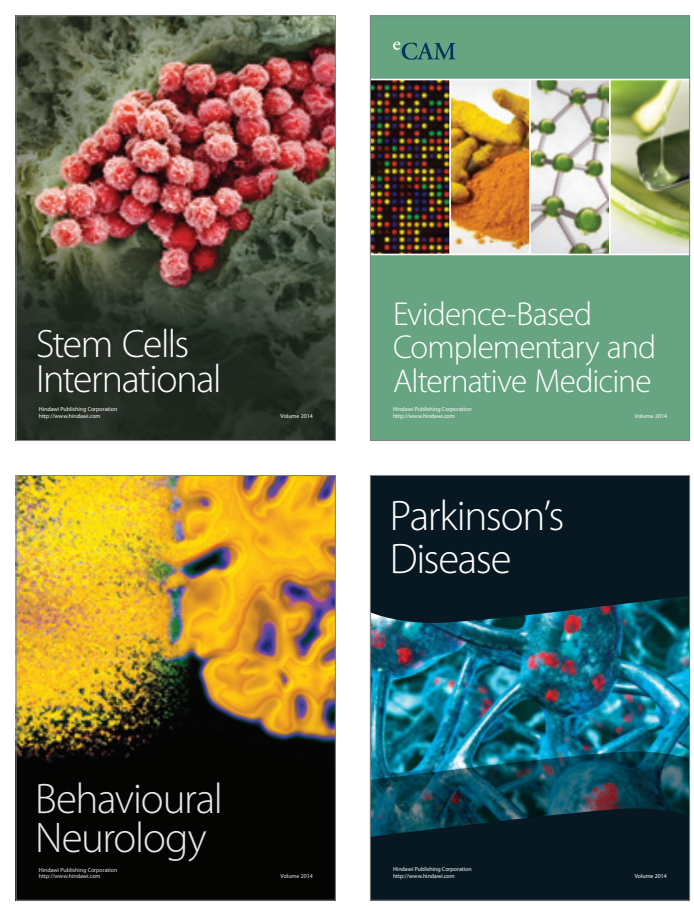

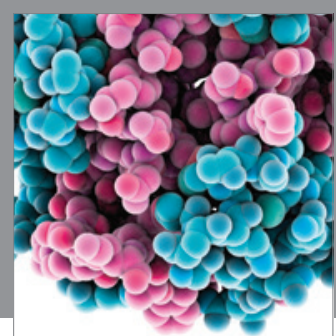

Journal of
Diabetes Research

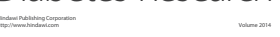

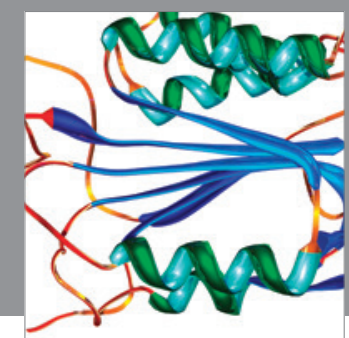

Disease Markers
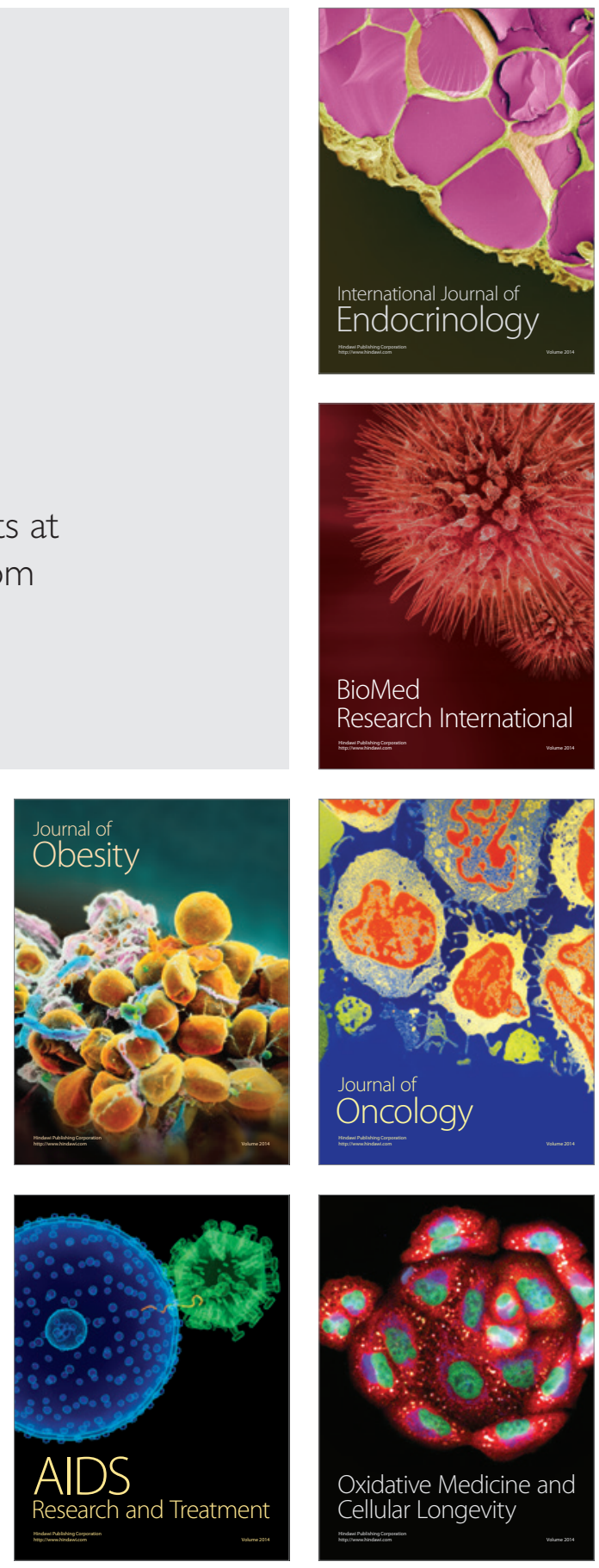